\title{
Visita Domiciliar em Saúde Mental - O Papel do Psicólogo em Questão
}

Mental health home visits - The psychologist's role

Ana Paula da Cunha

Pietroluongo

\& Tania Inessa Martins

de Resende

Centro Universitário

de Brasília 


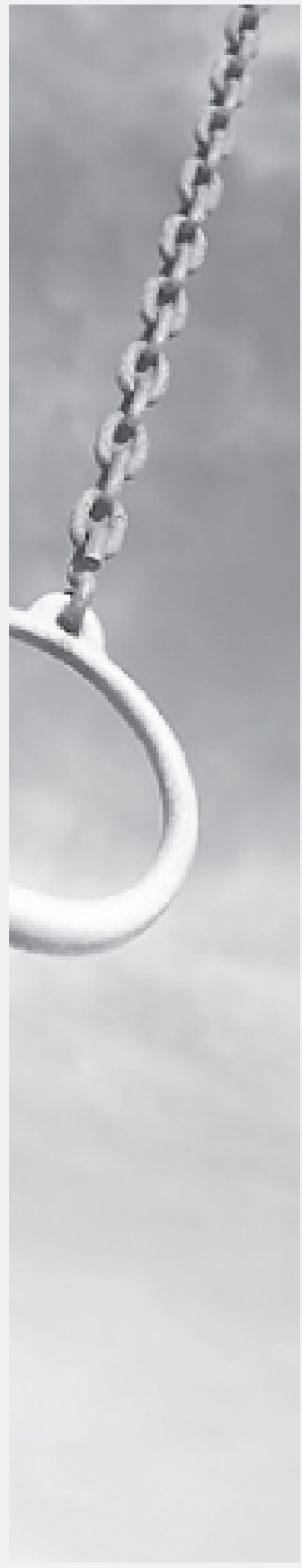

Resumo: Este artigo tem por objetivo principal discutir a visita domiciliar em saúde mental, refletindo acerca dos sentidos construídos nas relações estabelecidas entre os membros da equipe multidisciplinar, entre equipe e família e intermembros do sistema familiar, e, assim, contribuir para a capacitação familiar e conseqüente inclusão social do usuário de saúde mental. Tendo como base a experiência em um hospital psiquiátrico do DF, foi delineada uma tríade atitudinal para ancorar este trabalho dentro dos pressupostos da reforma psiquiátrica: a ética, a ação teórica e a postura reflexiva. Concluiu-se que é a partir do questionamento de conceitos já naturalizados sobre a doença mental como incapacitadora e alienante, e a família como culpada e incapaz de cuidar, que o usuário pode ter a sua cidadania retomada. Por ser conhecedor da importância das relações para a construção de sentidos e pela sua disponibilidade para a escuta, definiu-se o papel do psicólogo dentro da equipe, na visita domiciliar, como precursor dessa mudança relacional.

Palavras-chave: visita domiciliar, tríade atitudinal, capacitação familiar, inclusão social.

Abstract: This article discusses the home visiting in mental health, bringing up the meaning of the relationships built among the staff members, inside the family attended and its members and among the staff and the family.This way it can contribute to the family development and to the user social inclusion. The study basis is an experience in a psychiatric hospital and an attitude triangle was designed inside the psychiatric reform principles: ethics, theoric action and reflexive atitude. Conclusions are that questioning concepts as the inability of the psychiatric patient to deal with the world, the family as the main question leading to the disease and its inability to take care of the patient can lead the user to regain his citizenship. Since the psychologist knows the importance of the relations for the building of meaning and due to his capacity of listening to others, his role in the home visiting staff was defined as the forerunner of this relationship change.

Key-words: home visiting, attitude triangle, family development, social inclusion. 
Diante do pressuposto da reforma psiquiátrica de desinstitucionalização, proposto por Basaglia (1985), o núcleo de atenção ao usuário de saúde mental deixa de ser o hospital psiquiátrico, e seu acompanhamento passa a estar diluído em vários centros de atenção territorializados, como, por exemplo, CAPS/ NAPS, hospitais-dia, hospitais-noite, residências terapêuticas, dentre outros. O atendimento territorializado é importante, já que a desinstitucionalização tem como principal objetivo a inclusão social do "louco", investindo em relações de apoio ao diferente dentro da comunidade.

Como o usuário não vai estar mais recluso em uma instituição total (Goffman, 2003), mas sim, presente na sua comunidade, um acompanhamento comunitário e familiar se faz necessário. Com isso, pode-se dizer que a comunidade, bem como a família nuclear, serão os principais núcleos de acolhimento do sujeito com sofrimento mental grave. Os principais dispositivos utilizados para o acompanhamento da rede social do usuário são a visita domiciliar, mais focada no trabalho com o sistema familiar, e a terapia comunitária, focada no trabalho com a comunidade em geral.

Este artigo irá discutir a visita domiciliar, sua importância, os efeitos e o papel do psicólogo dentro desse processo. Tomará por base a vivência prática das autoras - em suas distintas funções de estagiária e supervisora - em um programa de visita domiciliar, implantado em um hospital do DF. Com base na Lei $n^{\circ}$ 10.216, de 06.04.2001, que atende aos pressupostos da reforma psiquiátrica, esse projeto tem por objetivo prestar atendimento em domicílio para os pacientes que já passaram pela internação psiquiátrica, visando ao seu acompanhamento e reintegração social. O trabalho de visita domiciliar faz todo o sentido, já que, com a desconstrução da loucura como doença e reconstrução desta enquanto um fenômeno complexo e existencial, a família é incluída no processo de tratamento, ou seja, como fenômeno multideterminado, a família tem um papel de extrema importância no acompanhamento do sujeito que sofre, já que várias relações são estabelecidas no convívio com o usuário, relações essas que vão construir lugares e formas de agir dentro do sistema familiar.

Com a construção da loucura enquanto doença orgânica, a família se sente, cada vez mais, excluída do processo de tratamento por não ter o instrumental necessário para lidar com uma doença de fundo estritamente orgânico. Além disso, com as primeiras construções dos saberes “psi” acerca do desenvolvimento infantil e da etiologia de alguns transtornos, a família passa, também, a se sentir culpabilizada, fracassada em educar.

Essa visão faz com que a família se sinta cada vez menos capaz de resolver os seus problemas e mais dependente dos técnicos que detêm o saber, construindo o que Brandão (2001) chama de ciclo de dependência.

É importante ressaltar que a inclusão da família no tratamento só é possível a partir do momento em que se questiona a episteme do paradigma médico dominante, ou seja, a partir desse questionamento, amplia-se a visão acerca do tratamento da loucura - que deixa de ser apenas medicamentoso e passa a abarcar a sua complexidade discursiva/ relacional e psicodinâmica.

De acordo com Brandão (2001), o atendimento domiciliar reflete as limitações do atendimento institucional e da atuação individual do profissional, e, em saúde mental, dentro dos pressupostos da reforma psiquiátrica, de busca da inclusão social do louco pela quebra de padrões culturais e pela forma de ver a loucura como um fenômeno complexo, a limitação da instituição e do profissional se faz mais evidente. 
Pode-se dizer que o objetivo primordial da visita domiciliar é buscar a capacitação das famílias para que estas possam utilizar recursos próprios, a fim de resolverem os seus problemas, incluindo-as no processo de tratamento (Brandão, 2001), já que é só a partir dessa capacitação que a família pode se sentir segura e confiante para lidar com os problemas suscitados com o convívio com a loucura, evitando as internações recorrentes e a conseqüente alienação social e a cronificação do usuário de saúde mental.

A partir do paradigma emergente, onde se coloca a importância da crítica epistemológica para conseguir alcançar o sujeito que sofre, desconstruindo pré-conceitos elaborados e construídos socialmente, fala-se da necessidade de o profissional ter uma escuta diferenciada, escuta essa que abarque o sujeito, sem julgamentos ou tentativas de encaixe deste na teoria. É importante salientar que a crítica epistemológica é um dos princípios norteadores da reforma psiquiátrica.

Tenório (2001) destaca que um técnico só pode chegar a compreender o sujeito e a família a partir do momento em que ele se permite sempre ser surpreendido com algo novo que surge no relacionamento, questionando os seus conceitos a priori. Essa atitude contribui para o surgimento de momentos de subjetivação.

Enfocando a visita domiciliar, para que o profissional possa abarcar a dinâmica familiar subjetiva, é necessária a modificação do conceito e da culpa dos familiares com a conseqüente valorização de seus saberes e habilidades e da loucura enquanto doença orgânica e incapacitante, devolvendo o poder de verdade à palavra do louco (Tenório, 2001). No momento em que a equipe, dentro do processo de visita domiciliar, abre a possibilidade de subjetivação, a partir da desconstrução da psicose enquanto doença, vendo-a como saída existencial legítima, outras facetas do sujeito que sofre começam a surgir, seu discurso passa a ser valorizado bem como a sua capacidade para escolher e para resolver problemas. A família pode começar a ver esse sujeito como um novo ser, alguém não mais idealizado, normatizado, mas sim, um sujeito que, apesar, por exemplo, de delirar, tem muito a contribuir para o sistema familiar e social. Este novo olhar pode ajudar o sujeito a encontrar novos lugares nos sistemas aonde está inserido

Com isso, pode-se concluir que um dos objetivos principais da equipe, na visita domiciliar, está na tentativa de integração e de fazer compreender o discurso psicótico, já que é só a partir dessa compreensão que novos sentidos para os problemas demandados pela família podem ser descobertos, ampliando a possibilidade de implementação de futuras ações.

A valorização das saídas que a própria família encontra para os impasses suscitados, bem como a busca da habilidade de cada membro do sistema para resolver os problemas pontuais colocados na visita, também são procedimentos que caracterizam a importância da visita domiciliar. Essa valorização só é possível, como já foi explicitado anteriormente, a partir da substituição das imagens sociais culpabilizadoras e incapacitadoras que o técnico em saúde mental, assim como a sociedade, pode ter da família.

É a partir dessa valorização que a família pode se sentir segura e autônoma, construindo as suas saídas para a resolução de problemas. Com isso, pode-se notar que essa segurança favorece a sua autonomia e a independência com relação à instituição de referência, atingindo, assim, o objetivo de capacitação familiar.

De acordo com Silva (2001), a doença mental é caracterizada por sua multidimensionalidade
A família pode começar a ver esse sujeito como um novo ser, alguém não mais idealizado, normatizado, mas sim, um sujeito que, apesar, por exemplo, de delirar, tem muito a contribuir para o sistema familiar e social, com a possibilidade de que ele encontre um novo lugar nos sistemas em que está inserido. 
e multideterminação, e, com isso, deve ser abarcada em todos os campos: biológico, psicológico, individual, familiar e social. Para alcançar esse objetivo, o trabalho em equipe multidisciplinar se faz de grande importância por sua heterogeneidade de saberes. Essa característica da equipe permite aos profissionais ter uma visão ampliada do fenômeno da loucura.

Um outro ponto de grande importância na visita com equipe multidisciplinar é que esse trabalho permite, também, que o sujeito que sofre e sua família tenham maiores possibilidades de vinculação afetiva com alguns dos profissionais, sejam eles quem forem. Esse profissional seria o técnico de referência, no qual a família se apoiaria para falar de seu sofrimento.

A equipe multidisciplinar pode ser estruturada de duas formas: vertical e horizontal. A estrutura verticalizada ou hierarquizada, em saúde mental, é marcada pela soberania do saber médico sobre os demais saberes. Esse tipo de estrutura está fundado no princípio básico da psiquiatria tradicional de loucura enquanto doença eminentemente orgânica. Já a estrutura horizontalizada remete a uma relação de aliança entre os saberes, onde a loucura é vista como plurideterminada, e, com isso, como um fenômeno de ordem existencial e psicodinâmico. Tal estrutura está mais condizente com o modelo de reforma psiquiátrica que passa a ver a loucura enquanto um fenômeno de ordem complexa, abarcando a existência do sujeito em sua totalidade (biológica, psicológica, social/ relacional). Nesse sentido, o médico seria mais um membro da equipe e o fator biológico não seria a causa determinante, mas sim, mais um fator que contribui para a manutenção do sofrimento psíquico grave.

A horizontalização dos saberes faz todo o sentido dentro da reforma psiquiátrica, pois é só a partir dessa ampliação da visão sobre o fenômeno da loucura, resultado da valorização de diversos e diferentes saberes/percepções acerca de um problema específico, que se pode alcançar o sujeito, podendo compreender sua subjetividade sem dicotomizá-lo em uma teoria específica, além de poder compreender, também, a família em sua totalidade, já que esta, dentro de uma visão complexa sobre a doença mental, tem um papel primordial para o acompanhamento desse sujeito em sua lida com o social.

Assim, nota-se que as relações intermembros da equipe, dentro dos pressupostos reformistas, deixam de ser relações de poder unidirecional, onde o saber da psiquiatria delimitava os outros saberes, para serem relações de horizontalidade, onde todo saber soma, sendo mais uma contribuição na forma de ver o problema suscitado pela família, o que amplia, assim, as possibilidades de solução. Pode-se dizer que a horizontalização, por seu princípio básico de valorização dos diversos saberes, conta com uma construção conjunta intermembros da equipe, entre a equipe e a família e intermembros da família acerca das saídas possíveis para os problemas suscitados pelo sistema familiar.

Com isso, conclui-se que é apenas com a horizontalização dos saberes dentro da equipe que o trabalho multidisciplinar pode fazer sentido em saúde mental, já que essa horizontalização conta com um questionamento epistemológico maior, e, assim, dá abertura para se compreender o sujeito em sua complexidade e multideterminação.

\section{As três dimensões atitudinais}

Diante da importância da visita domiciliar enquanto dispositivo que ajuda na inclusão social do sujeito com sofrimento mental grave, que tipo de relação deve ser estabelecida para que a família e o sujeito possam, realmente, estar no lugar de sujeitos capacitados para lidar com seus problemas? Postulamos três dimensões atitudinais que são de fundamental 
importância para que se consiga alcançar o objetivo de capacitação do núcleo familiar: a ética, a ação-teórica e a postura reflexiva.

De acordo com Araújo (2003), para se trabalhar em saúde mental dentro dos pressupostos reformistas, faz-se necessária a construção de uma ética para a loucura, pois, além de a ética ser o princípio norteador de qualquer prática profissional em saúde mental, esta também perpassa pela questão da reconstrução da moralidade, ou seja, a atitude ética não seria apenas uma tentativa de reprodução da moral, mas sim, uma reconstrução desta a partir do contato com o outro.

A transformação do social é um dos princípios da luta antimanicomial. Segundo Lobosque (1997), é necessária uma flexibilização dos limites sociais para "fazer caber" a diferença. É só a partir dessa flexibilização que pode existir, realmente, uma inclusão social.

Segundo Guarechi (2003), a ética seria definida como uma postura crítica, na relação dialógica com o outro, diante de todo conceito criado e institucionalizado. Essa dimensão da ética discute a importância da transformação, do aperfeiçoamento de todo o criado que, no caso específico da doença mental, seria o discurso normatizador e culpabilizador da família, para que se possa ser ético, justo com o outro.

Assim, pode-se dizer que a transformação da moral, em visita domiciliar, teria como ponto de partida a destituição da imagem social da família enquanto culpada e incapacitada de cuidar. Só assim pode-se entrar no cerne do sofrimento familiar, encapsulado pela normatização, e, desse sofrimento, buscar a saúde que existe no sistema, permitindo que os membros da família se sintam valorizados e seguros para encontrar soluções criativas para o seu sofrimento.

Segundo Neubern (2004), a ação teórica é definida como "um conjunto de princípios que evitam a tentativa da cosmovisão e narrativa, ou ainda, a tentativa de moldar os pacientes em princípios universais” (p. 122). Com isso, pode-se entender que a ação teórica tem por objetivo evitar a "objetalização" do sujeito ao pressuposto teórico dominante da equipe, ou seja, que esse pressuposto não seja o norte principal em que a equipe se baseia para construir sentidos acerca das experiências vivenciadas na visita domiciliar, mas sim, que o sentido das experiências sejam resgatados na família, tendo por base seu cenário subjetivo.

Ainda de acordo com Neubern (2004), a teoria, como qualquer construto a priori, deve ser apenas uma referência, um ponto inicial na tentativa de se apreender a dinâmica familiar, e não um critério absoluto de verdade. Nesse caso, a relação se inverte, já que, do singular, se constrói um geral, que pode e deve estar aberto às novas construções e interpretações. Essa visão vai de encontro à visão atual legitimada pelo paradigma dominante, em que, do geral naturalizado, constrói-se o singular (leis universais).

Dentro dessa dimensão da ação teórica, a teoria ganha o status de dinamicidade e historicidade, ou seja, a teoria ou a técnica é sempre relacionada a um sujeito específico, está sempre aberta ao novo, ao singular de cada dinâmica familiar. Segundo Gonzalez Rey (2002), essa nova forma de atuação fala da transição de uma epistemologia da resposta para uma epistemologia da construção.

Para que a família possa emergir enquanto fenômeno singular e único na relação com o técnico, a postura reflexiva, também, se faz de grande importância. O sujeito é formado pelo social, ou seja, pelos espaços sociais em que circula. Esses espaços sociais são de fundamental importância para a percepção que o sujeito vai construir acerca de si e do mundo, fundando a sua configuração subjetiva, sendo que, a partir dessa configuração, o sujeito vai
Assim, pode-se dizer que a transformação da moral, em visita domiciliar, teria como ponto de partida a destituição da imagem social da família enquanto culpadae incapacitada de cuidar. 
atribuir sentidos aos fenômenos observados e agir de acordo com esse sentido.

Um dos espaços sociais em que os técnicos circulam é a própria instituição psiquiátrica, que reproduz os construtos do paradigma dominante passados na formação acadêmica e moral: o técnico tem o saber, o usuário está fora de si e precisa ser tutelado e ser paciente, a loucura é uma doença orgânica, e a família é incapaz de cuidar se não tiver a instrumentalização necessária, que se adquire a partir do conhecimento técnico.

Com isso, o técnico constrói os conceitos sobre si, enquanto profissional, baseado nesses construtos, além de também estar inserido no senso comum, que reproduz vários mitos relacionados à loucura e à família. Dessa forma, pode-se dizer que, para se construir uma relação que subjetive a família, é necessária uma reforma pessoal, de reflexão acerca dos valores dos próprios profissionais, construídos nos seus espaços sociais e concretizados nas atitudes que estes constroem com a família e com o usuário de saúde mental.

É a partir da reflexão de quais valores subjetivos do técnico estão sendo passados no discurso, e que lugar está sendo construído para a família a partir deste discurso, que o técnico pode se diferenciar da família e buscar uma relação onde essa possa surgir enquanto singularidade. É importante lembrar que a ética e a ação teórica só ganham vida na relação pela postura reflexiva, já que, como já foi discutido anteriormente, a equipe dá sentido aos conceitos a priori acerca de um sujeito específico, sentido esse que é subjetivo e diz da configuração subjetiva de cada técnico. Logo, a teoria e a moral não são puras, mas sim, pessoalizadas.

Além dessa dimensão da auto-reflexão, a postura reflexiva também deve estar presente em uma outra dimensão: a de refletir com a família. Segundo Guidano (1997), o sujeito não observa o objeto, mas sim, experencia-o a partir de seu próprio corpo. “Como seres humanos, não podemos fugir da nossa maneira particular de ser” (p. 79).

A partir do momento em que se entende a percepção de um dado fenômeno enquanto intrinsecamente ligado à configuração subjetiva de quem observa, pode-se dizer que um fenômeno nunca é visto de maneira pura, mas sim, personalizada.

Dessa forma, Andersen (1998) cita a existência de tantas versões de uma dada situação quantos forem os sujeitos que a observam. Assim, a reflexão com a família tem por objetivo desconstruir a relação ou-ou, onde apenas um discurso traz a verdade, para construir a relação tanto-como, horizontalizando o saber entre equipe e família. Seria a passagem da atribuição de um saber único para o compartilhamento desse saber (idem, 1998).

Com isso, percebe-se que a postura reflexiva ou reflexividade é um conceito que está ancorado em duas dimensões diretamente relacionadas e que necessariamente devem estar presentes na relação com a família: a auto-reflexão, que permite que cada sujeito perceba de que forma os seus valores estão influenciando a forma de perceber a família e de construir um lugar para esta, e a reflexão conjunta, que proporciona um compartilhamento de percepções entre equipe e família e amplia a compreensão acerca da dinâmica familiar.

Pelo que foi discutido, conclui-se que, a partir de uma relação ancorada nas três dimensões atitudinais (ética, ação teórica e postura reflexiva), pode-se construir um novo lugar para a família, lugar onde se possa concretizar o objetivo da visita domiciliar de capacitação do sistema familiar e, assim, ajudar na concretização do objetivo principal da reforma 
psiquiátrica: a inclusão social e cidadania do usuário de saúde mental.

\section{O papel do psicólogo}

De acordo com a prática vivenciada que está em reflexão no presente artigo, o psicólogo, por sua formação diferenciada, pode ter um papel fundamental dentro da equipe multidisciplinar, a escuta. É a partir da escuta que o profissional pode proporcionar momentos de subjetivação do sistema familiar, favorecendo a ampliação da percepção da equipe e da própria família acerca dos problemas suscitados por esta.

Um outro papel do psicólogo, que está intimamente ligado ao seu papel principal de escuta, é a de ser um intermediador entre a instituição e a família, ajustando as demandas e "limpando" os canais de comunicação. Essa atitude, em muitos momentos, é necessária, já que a equipe institucional, pela grande demanda de visitas e falta de instrumental teórico, muitas vezes pode entrar em conflito com as famílias, conflitos esses que podem ser solucionados pelo diálogo intermediado.

Muitos conflitos que podem surgir entre equipe e família estão ligados à tentativa de “objetalização” dessa família pela equipe. Essa “objetalização” é realizada como uma tentativa de negação da impotência por parte da equipe. A partir da vivência no projeto "Vida em Casa", observou-se que a saída encontrada pelos técnicos para lidar com a impotência era, muitas vezes, a instauração das relações de violência.

Com isso, um outro papel do psicólogo surge: o acolhimento da própria equipe. Esse acolhimento pode ser de grande importância para os membros da equipe, incluindo o próprio psicólogo, para estes poderem suportar estar no lugar de não-saber, mesmo que a família lhes atribua o poder de saber.

A posição de não-saber exige, em muitos momentos, a reflexão acerca dos valores de cada técnico, e, por outro lado, traz a limitação teórica de sua atuação. Dessa forma, o acolhimento pode ajudar a equipe a encontrar novas formas de lidar com a própria impotência, suscitada pelo contato com a loucura e com a configuração familiar.

Além dos papéis de acolhimento e intermediação realizados pelo psicólogo, este, como conhecedor da função das relações dialógicas na construção de sentidos subjetivos, bem como do papel dos construtos sociais na construção dessas relações, pode exercer, também, o papel de incentivador da reflexão técnica dentro da equipe. Ressalta-se que o acolhimento e a intermediação são resultado da postura de escuta do profissional de Psicologia. Em outras palavras, por conhecer os processos relacionais, o psicólogo pode ajudar a compreender, dentro de um espaço social, que lugares estão sendo construídos para os sujeitos (equipe, usuários e família) e de que forma podem-se construir novas relações para que esses lugares sejam condizentes com os pressupostos da reforma. Com isso, pode-se notar que é a partir da crítica epistemológica, concretizada na posição do psicólogo dentro da equipe, pela escuta diferenciada, que novas formas de se relacionar com a família e com os próprios membros da equipe vão sendo delimitadas, e, assim, buscando a capacitação da família ao invés da normatização desta, e a inclusão do sujeito que sofre ao invés da sua exclusão e punição por ser diferente.

É importante salientar que qualquer profissional é capaz de estabelecer relações que favoreçam a capacitação familiar. Se assim não fosse, o saber soberano apenas mudaria de especialidade, deixando de ser a psiquiatria para ser a Psicologia. Como a reforma tem como principal pressuposto a desconstrução da loucura enquanto doença eminentemente orgânica, para ser vista em sua complexidade, não faz o menor sentido instituir um poder 
soberano ao psicólogo, já que, da mesma forma que no paradigma psiquiátrico, a visão da loucura e da família seria reduzida, nesse caso, ao viés psicodinâmico.

Na equipe multidisciplinar, o grande desafio para todos os técnicos é não só poder conhecer o seu papel mas também conseguir valorizare reconhecer o papel do outro como de

fundamental importância para se ter uma visão complexa dos fenômenos. Só assim pode-se ter uma equipe horizontalizada, aberta à reflexão e a novas alternativas relacionais e de ação terapêutica.

Assim, pode-se dizer que o psicólogo, pelo seu papel de escuta, pode ser o precursor do movimento de reflexão e mudança. É importante ressaltar que essa escuta diferenciada e conseqüentes acolhimento, compreensão e mediação só são possíveis se a formação desse psicólogo, assim como sua atuação, privilegiarem o sujeito, o conhecimento e a compreensão deste, ao invés da pura "objetalização" e "psiquiatrização" do social.

Na equipe multidisciplinar, o grande desafio para todos os técnicos é não só poder conhecer o seu papel mas também conseguir valorizar e reconhecer o papel do outro como de fundamental importância para se ter uma visão complexa dos fenômenos. Só assim pode-se ter uma equipe horizontalizada, aberta à reflexão e a novas alternativas relacionais e de ação terapêutica.

\section{Conclusão}

A partir do que foi discutido, pode-se concluir que, para ser um sujeito que tem seu lugar na comunidade, o louco deve recobrar as suas referências afetivas e sociais. Só assim ele pode sair da alienação que a instituição da exclusão promove. Para ter de volta essas referências, é importante que esse sujeito em sofrimento retorne à sua rede social. Esta deve se sentir capaz de lidar com esse sujeito, sentindo-se parte integrante do tratamento. É nesse momento que a visita domiciliar pode ter um papel fundamental de capacitação do sistema familiar para que este possa se sentir seguro e confiante, podendo lidar com os problemas suscitados pelo convívio com a loucura sem a dependência dos técnicos.

Salienta-se que, em muitos momentos, o atendimento técnico é de grande relevância para o sujeito com sofrimento psíquico grave. Assim, mesmo com o atendimento domiciliar, é importante que esse sujeito tenha outras possibilidades de ser assistido, outros projetos terapêuticos dos quais possa participar. Segundo Tenório (2001), há de haver tantos projetos terapêuticos quantos forem os sujeitos que sofrem.

O objetivo de capacitação familiar, como já foi colocado, só pode ser atingido se o profissional de saúde mental buscar uma nova postura relacional, saindo da "objetalização" e normatização do diferente e do seu sistema familiar. Essa postura pode estar ancorada, de acordo com este artigo, em três dimensões atitudinais: a ética, na busca da transformação do social; a ação teórica, que tem por objetivo a flexibilização teórica para fazer caber a diferença, e a postura reflexiva, de fundamental importância para que as outras duas dimensões possam, de fato, se concretizar e, assim, atingir a epistemologia da construção.

Além disso, neste artigo, foi discutida a importância do trabalho em equipe. Segundo Brandão (2001), “a intervenção em equipe possibilita que diferentes olhares auxiliem a criação de diferentes hipóteses” (p. 90). Só assim pode-se tentar vislumbrar a complexidade do sistema familiar e da loucura. Dessa forma, pode-se dizer que o papel do psiquiatra na reforma foge do lugar central de atendimento à loucura, deixando de ser o profissional de referência e passando a ser equiparado aos outros saberes. Diante da visão da loucura enquanto complexidade, todos os aspectos da vivência do sujeito passam a ser considerados: sua configuração subjetiva, seu corpo fisiológico e a relação desse sujeito e sua família com o social.

De acordo com o que foi discutido, pôde-se concluir que, para se ter essa visão ecológica do adoecimento mental e da configuração familiar, faz-se necessária uma horizontalização dos saberes dentro da equipe, horizontalização 
essa que pode ser promovida, inicialmente, pelo profissional da Psicologia.

Esse profissional, por sua postura diferenciada de escuta, pode, dentro da equipe, ajudar na ampliação acerca da percepção de um problema específico suscitado pela família; fazer o papel de intermediação entre a equipe e a família; e incentivar a reflexão técnica intermembros da equipe.Todos esses papéis só podem ser alcançados se esse profissional tiver uma formação diferenciada, de crítica epistemológica, deixando de ser um profissional de reprodução e controle social para ser um profissional transformador desse social. Desta forma, sua atuação vai estar ancorada nas três dimensões atitudinais discutidas neste trabalho.

É só a partir dessa nova formação que o psicólogo pode privilegiar o sujeito, sua configuração subjetiva, subjetivando a demanda do usuário e de seu sistema familiar e ajudando a buscar as habilidades dentro do sistema para resolver os problemas suscitados, e, assim, buscar, propriamente, a saúde mental ao invés da doença.

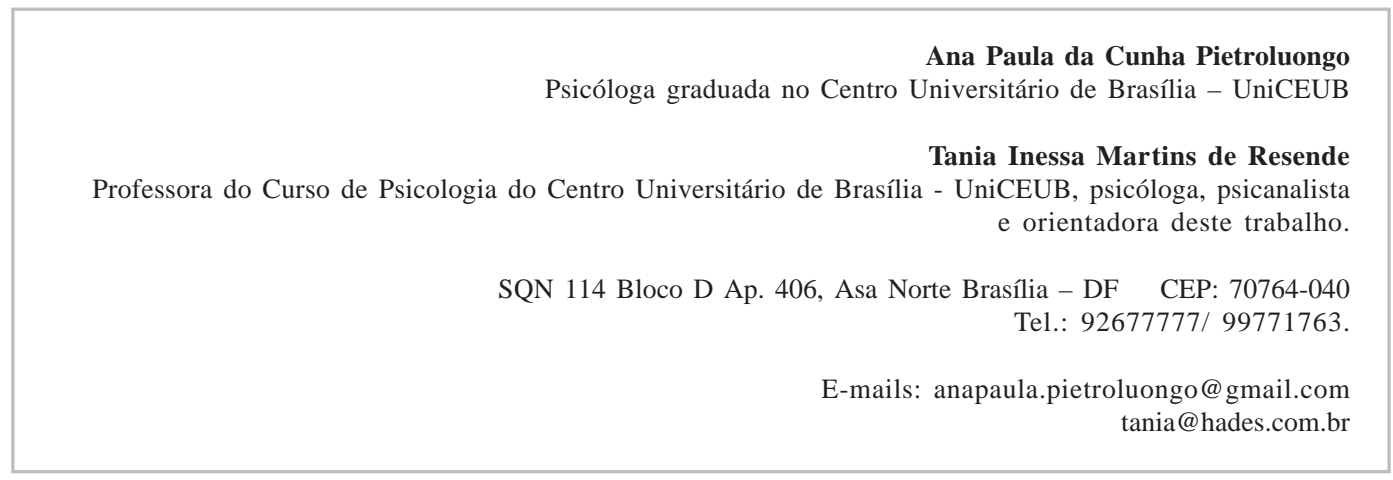

Recebido 13/02/06 Reformulado 18/07/06 Aprovado 24/07/06

ANDERSEN, T. Reflexões sobre a Reflexão com Famílias. In: McNamee, S. \& Gergen, K. A Terapia como Construção Social. Porto Alegre : Artes Médicas, 1998.

ARAÚJO, E. O Mundo Vivido de Eduardo de Araújo. In: CFP, Loucura, Ética, Política: Escritos Militantes. São Paulo: Casa do Psicólogo, 2003.

BASAGLIA, F. A Instituição Negada. Rio de Janeiro: Graal, 1985.

BRANDÃO, S. N. Visita Domiciliar: Ampliando Intervenções Clínicas em Comunidade de Baixa Renda. Dissertação de Mestrado, defendida na Universidade de Brasília, 2001.

GOFFMAN, E. Manicômios, Prisões e Conventos. São Paulo: Perspectiva, 2003.

GONZALEZ, F. R. Pesquisa Qualitativa em Psicologia - Caminhos e Desafios. São Paulo: Pioneira Thomson Learning, 2002.
GUARECHI, P. Ética, Justiça e Direitos Humanos. In: CFP, Os Direitos Humanos na Prática Profissional dos Psicólogos. Comissão Nacional de Direitos Humanos do Conselho Federal de Psicologia, 2003.

GUIDANO, V. F. Psicoterapia Construtivista: uma Estrutura Teórica. In: Neimeyer, R. A. \& Mahoney, M. J. Construtivismo em Psicoterapia. Porto Alegre: Artes Médicas, 1997.

LOBOSQUE, A. M. Princípios para uma Clínica Antimanicomial. São Paulo: Hucitec, 1997.

NEUBERN, M. S. Complexidade e Psicologia Clínica: Desafios Epistemológicos. Brasília: Plano, 2004.

SILVA, L. B. Doença Mental, Psicose e Loucura: Representações e Práticas da Equipe Multiprofissional de um Hospital-dia. São Paulo: Casa do Psicólogo, 2001.

TENÓRIO, F. APsicanálise e a Clínica da Reforma Psiquiátrica. Rio de Janeiro: Ambiciosos, 2001. 